\title{
Cancers attributable to excess body weight in Canada in 2010
}

\section{Dianne Zakaria, PhD; Amanda Shaw, MSc}

This article has been peer reviewed.

\begin{abstract}
Introduction: Excess body weight (body mass index $[\mathrm{BMI}] \geq 25.00 \mathrm{~kg} / \mathrm{m}^{2}$ ) is an established risk factor for diabetes, hypertension and cardiovascular disease, but its relationship to cancer is lesser-known. This study used population attributable fractions (PAFs) to estimate the cancer burden attributable to excess body weight in Canadian adults (aged $25+$ years) in 2010 .
\end{abstract}

Methods: We estimated PAFs using relative risk (RR) estimates from the World Cancer Research Fund International Continuous Update Project, BMI-based estimates of overweight $\left(25.00 \mathrm{~kg} / \mathrm{m}^{2}-29.99 \mathrm{~kg} / \mathrm{m}^{2}\right)$ and obesity $\left(30.00+\mathrm{kg} / \mathrm{m}^{2}\right)$ from the $2000-2001$ Canadian Community Health Survey, and cancer case counts from the Canadian Cancer Registry. PAFs were based on BMI corrected for the bias in self-reported height and weight.

Results: In Canada in 2010, an estimated 9645 cancer cases were attributable to excess body weight, representing $5.7 \%$ of all cancer cases (males $4.9 \%$, females $6.5 \%$ ). When limiting the analysis to types of cancer associated with high BMI, the PAF increased to $14.9 \%$ (males $17.5 \%$, females $13.3 \%$ ). Types of cancer with the highest PAFs were esophageal adenocarcinoma (42.2\%), kidney (25.4\%), gastric cardia $(20.7 \%)$, liver $(20.5 \%)$, colon $(20.5 \%)$ and gallbladder $(20.2 \%)$ for males, and esophageal adenocarcinoma $(36.1 \%)$, uterus $(35.2 \%)$, gallbladder $(23.7 \%)$ and kidney $(23.0 \%)$ for females. Types of cancer with the greatest number of attributable cases were colon (1445), kidney (780) and advanced prostate (515) for males, and uterus (1825), postmenopausal breast (1765) and colon (675) for females. Irrespective of sex or type of cancer, PAFs were highest in the Prairies (except Alberta) and the Atlantic region and lowest in British Columbia and Quebec.

Conclusion: The cancer burden attributable to excess body weight is substantial and will continue to rise in the near future because of the rising prevalence of overweight and obesity in Canada.

Keywords: population attributable fraction, body mass index, overweight, obesity, cancer

\section{Introduction}

The burden of cancer on the Canadian population is heavy. Currently, the lifetime risk of developing cancer is $45 \%$ for males and $42 \%$ for females, ${ }^{1}$ and cancer is the leading cause of death in Canada, accounting for $30 \%$ of all deaths in $2012 .^{2}$ Consequently, understanding the main drivers of the cancer burden is a public health priority. Population attributable fractions (PAFs) can be used to quantify the impact of different factors on the occurrence of cancer in a population and thus are of value in prioritizing cancer control strategies. Assuming a causal relationship between a specific factor and cancer, the PAF estimates the proportion of cancer cases that could be prevented by eliminating the specific factor from the population. ${ }^{3,4}$ In a recent British study using PAFs to estimate the proportion of cancers attributable to lifestyle and environmental risk factors, tobacco use, diet and excess body weight were identified as the top three risk factors, accounting for $19.4 \%, 9.2 \%$ and $5.5 \%$ of all cancers, respectively. ${ }^{5}$
Highlights

- An estimated 9645 cancer cases or $5.7 \%$ of all cancers diagnosed in Canadian adults (aged $25+$ years) were attributable to excess body weight in 2010.

- Cancers with the greatest proportion of cases attributable to excess body weight included esophageal adenocarcinoma, kidney, gastric cardia, liver, colon and gallbladder for males, and esophageal adenocarcinoma, uterus, gallbladder and kidney for females.

- Cancers contributing the greatest number of cases attributable to excess body weight were colon, kidney and advanced prostate for males, and uterus, postmenopausal breast and colon for females.

- The proportion of cancers attributable to excess body weight was highest in the Prairies (except Alberta) and the Atlantic region, and lowest in British Columbia and Quebec.

Although excess body weight is an established risk factor for diabetes, hypertension and cardiovascular disease, its relationship to cancer is lesser-known. ${ }^{6}$ In 2002, the International Agency for Research on Cancer concluded that excess body weight is associated with an increased risk of developing cancers of the colon, breast (postmenopausal), endometrium, kidney and esophagus (adenocarcinoma), ${ }^{6}$ and more recent systematic reviews have identified additional cancers. ${ }^{7-10}$ Cited potential carcinogenic mechanisms include hormonal and metabolic changes, elevated oxidative stress, stimulation of the body's inflammatory response and increased gastroesophageal reflux 
caused by the direct mechanical effects of central obesity. ${ }^{6,7,11}$

Several relatively recent studies have examined the proportion of cancers attributable to excess body weight in Canada ${ }^{12,13}$ and also specifically in Ontario. ${ }^{14}$ However, additional types of cancer have since been identified as having strong evidence of a causal relationship with excess body weight. As well, none of the previous research provided a comprehensive regional examination of PAFs in Canada. Considering the growing recognition of body weight as a risk factor for cancer and the rising prevalence of excess body weight in the Canadian population, ${ }^{15}$ more current, comprehensive estimates of the proportion of cancers attributable to excess body weight are needed to guide cancer control strategies. The primary objective of this study is to estimate the proportion and number of new cancer cases attributable to excess body weight in Canadian adults, aged 25 years and older, in 2010.

\section{Methods}

\section{Prevalence of excess body weight in the Canadian population}

We used body mass index (BMI), a commonly used measure with established cut points for excess body weight ${ }^{16}$ (defined as a BMI of $25.00+\mathrm{kg} / \mathrm{m}^{2}$; Table 1 ), to quantify the prevalence of overweight and obese Canadians. We used self-reported height and weight, obtained from the Canadian Community Health Survey (CCHS), ${ }^{17}$ to calculate BMI (weight in kilograms divided by squared height in metres). The CCHS, a population-based survey initiated in 2000, was designed to provide reliable estimates at the health region and provincial levels for the population aged 12 years and older, with some exclusions representing less than $3 \%$ of the Canadian population. Canadian research has demonstrated that BMI based on self-report is biased downward because

TABLE 1

\section{Body mass index categories}

\begin{tabular}{ll}
\multicolumn{1}{c}{ Category } & \multicolumn{1}{c}{ Cut points } \\
\hline Underweight & $<18.50 \mathrm{~kg} / \mathrm{m}^{2}$ \\
Normal & $18.50-24.99 \mathrm{~kg} / \mathrm{m}^{2}$ \\
Overweight & $25.00-29.99 \mathrm{~kg} / \mathrm{m}^{2}$ \\
Obese & $30.00+\mathrm{kg} / \mathrm{m}^{2}$ \\
\hline
\end{tabular}

Note: Categories defined according to the WHO Consultation on Obesity. ${ }^{16}$ people overreport their height and underreport their weight. ${ }^{18}$ Therefore, we adjusted BMIs for this study using correction formulas previously developed on a subsample of CCHS respondents who agreed to have their height and weight measured in addition to providing self-reports (Equations 1 and 2). ${ }^{19,20}$

To estimate the proportion of cancer cases in 2010 attributable to excess body weight, the prevalence of excess body weight in 2000 and 2001 was used to allow at least a 10-year latency period between exposure (excess body weight) and disease (cancer). For example, the proportion of cancers attributed to excess body weight among adults aged 45 to 54 years in 2010 was based on the prevalence of overweight and obese adults aged 35 to 44 years in 2000 and 2001. A 10-year latency was the longest possible period available using the CCHS, and is consistent with similar research ${ }^{12,21,22}$ as well as the range of geometric mean duration of follow-up in a comprehensive meta-analysis examining the association between body weight and several types of cancer. ${ }^{8}$ To acknowledge the sampling design of the CCHS, we weighted all estimates and obtained corresponding variance estimates using balanced repeated replication with the provided replicate weights. The national response rate for the CCHS in 2000 and 2001 was $84.7 \% .^{17}$

\section{Associations between excess body weight and cancer}

Cancers with strong evidence of a causal relationship with high BMI were identified through the World Cancer Research Fund (WCRF) International Continuous Update Project (CUP), an ongoing program analyzing global research on how diet, nutrition, physical activity and weight affect cancer risk and survival. ${ }^{23}$ The CUP completes thorough systematic reviews and meta-analyses primarily of randomized controlled trials, cohort and nested casecontrol studies. Estimates of association that are most adjusted for confounding and have adequate data for dose-response are used in the meta-analyses. These reviews are evaluated by an independent expert panel who draw conclusions regarding the strength of evidence supporting the relationships. Strong evidence is considered strong enough to generally justify recommendations designed to reduce the incidence of cancer. At a minimum, strong evidence includes the following: proof from at least two independent cohort studies or at least five case-control studies; no substantial unexplained heterogeneity; good-quality studies that exclude the possibility of random or systematic error; and biological plausibility. Additional criteria include evidence from more than one study type; the presence of a dose-response association; and strong and plausible human or animal experimental evidence that typical human exposures can lead to cancer. ${ }^{24}$

According to the WCRF International CUP, there is strong evidence supporting a causal relationship between high BMI and 12 cancers (Table 2 ). The sex-specific relative risk (RR) estimates extracted for this study were those based on cohort studies examining incident cancer as the outcome. We converted RR estimates associated with a five-unit increase in BMI to RR estimates for a one-unit increase in BMI by assuming a linear relationship between the natural logarithm of the RR and BMI. For males, the relative risk (RR) of cancer associated with a one-unit increase in BMI ranged from a low of 1.02 for pancreatic, rectal and advanced prostate cancer to a high of 1.09 for esophageal adenocarcinoma. For females, the increased risk ranged from 1.01 for rectal and ovarian cancer to 1.08 for esophageal adenocarcinoma and uterine cancer.

\section{Number of new cancer cases in Canada in 2010}

We obtained counts of new cancer cases for each province and territory, except Quebec, for the most recent year with complete national data (2010) from the Canadian Cancer Registry (CCR) (data file based on International Rules for Multiple Primary Cancers, ${ }^{35}$ released in September 2012). We downloaded case counts for Quebec in 2010 from Statistics Canada's website. $^{36}$ 
TABLE 2

Relative risk of 12 types of cancer associated with a one-unit increase in body mass index, by sex

\begin{tabular}{lcc} 
& \multicolumn{2}{c}{ Relative risk $(95 \% \mathrm{Cl})$} \\
\hline & Males & Females \\
Esophageal adenocarcinoma $^{24}$ & $1.09(1.07-1.12)$ & $1.08(1.05-1.11)$ \\
Gastric cardia $^{25, \mathrm{~b}}$ & $1.04(1.01-1.07)$ & $1.04(1.01-1.07)$ \\
Liver $^{26}$ & $1.04(1.00-1.08)$ & $1.04(1.02-1.06)$ \\
Gallbladder $^{27}$ & $1.04(1.02-1.06)$ & $1.05(1.01-1.08)$ \\
Pancreas $^{28}$ & $1.02(1.01-1.04)$ & $1.02(1.01-1.03)$ \\
Colon $^{29}$ & $1.04(1.03-1.05)$ & $1.02(1.01-1.03)$ \\
Rectum $^{29}$ & $1.02(1.01-1.02)$ & $1.01(1.00-1.02)$ \\
Kidney $^{30}$ & $1.05(1.04-1.06)$ & $1.05(1.04-1.06)$ \\
Advanced prostate $^{31}$ & $1.02(1.01-1.02)$ & NA \\
Postmenopausal breast $^{32}$ & NA & $1.02(1.02-1.03)$ \\
Uterus $^{33}$ & NA & $1.08(1.07-1.10)$ \\
Ovary $^{34}$ & NA & $1.01(1.00-1.02)$ \\
\hline
\end{tabular}

Abbreviations: $\mathrm{Cl}$, confidence interval; $\mathrm{NA}$, not applicable.

Note: Relative risk (RR) estimates associated with a five-unit increase in body mass index (BMI) were converted to RR estimates for a one-unit increase in BMI by assuming a linear relationship between the natural logarithm of the RR and BMI.

a Types of cancer identified by the World Cancer Research Fund International CUP. ${ }^{23}$

${ }^{\mathrm{b}}$ Estimates are for males and females combined, as sex-specific estimates were based on too few studies.

Cancer definitions were aligned with the meta-analysis quantifying their association with BMI (Table 3). Because staging information was not complete for all prostate cancers, particularly in certain provinces, we obtained estimates of the proportion of stage III and stage IV prostate cancers by age group using all staged prostate cancers diagnosed in Canada (excluding Quebec) during 2010.

Case counts for Quebec needed to be adjusted for a few cancers not directly available through Statistics Canada's website. Specifically, we estimated the number of esophageal adenocarcinomas and cancers of the gastric cardia and liver (including intrahepatic bile duct) for Quebec using information available for all provinces and territories except Quebec. For example, the proportion of esophageal cancers that were adenocarcinomas in Quebec were estimated using sex- and age-specific proportions for all of Canada, except Quebec, in 2010. For confidentiality reasons, presented case counts were randomly rounded to an adjacent multiple of 5 using an unbiased random rounding scheme; actual case counts ending in 0 or 5 were not rounded.

\section{Population attributable fractions (PAFs)}

We estimated PAFs specific to cancer, region, sex and age group as per Equation $3{ }^{4}$

The RR associated with a BMI category was quantified relative to $21 \mathrm{~kg} / \mathrm{m}^{2}$, an accepted optimal value, ${ }^{40}$ using Equation 4 . We assumed no risk for BMI less than $25.00 \mathrm{~kg} / \mathrm{m}^{2}$.

The product of the PAF specific to cancer, region, sex and age group and corresponding incident cancers provided the number of cancer cases attributable to excess body weight. Thereafter, summations across relevant strata (e.g. type of cancer, region, sex and age) provided PAFs and

TABLE 3

Definitions for cancers associated with excess body weight ${ }^{a}$

\begin{tabular}{|c|c|c|c|}
\hline Cancer & Topography & Histology & Other criteria \\
\hline $\begin{array}{l}\text { Esophageal } \\
\text { adenocarcinoma }\end{array}$ & C15.0-C15.9 & $\begin{array}{l}\text { 8050, 8140-8147, 8160-8162, 8180-8221, 8250-8507, 8514, } \\
8520-8551,8560,8570-8574,8576,8940-8941\end{array}$ & \\
\hline Liver & $\mathrm{C} 22.0, \mathrm{C} 22.1$ & excludes $9050-9055,9140,9590-9992$ & \\
\hline Gallbladder & C23.9 & excludes $9050-9055,9140,9590-9992$ & \\
\hline Pancreas & C25.0-C25.9 & excludes $9050-9055,9140,9590-9992$ & \\
\hline Rectum & C19.9, C20.9 & excludes $9050-9055,9140,9590-9992$ & \\
\hline Kidney & C64.9, C65.9 & excludes $9050-9055,9140,9590-9992$ & \\
\hline Prostate (advanced) & C61.9 & excludes $9050-9055,9140,9590-9992$ & AJCC stage III and IV \\
\hline Breast (postmenopausal) & C50.0-C50.9 & excludes $9050-9055,9140,9590-9992$ & Age 50 years and older \\
\hline
\end{tabular}

Abbreviation: AJCC, American Joint Committee on Cancer.

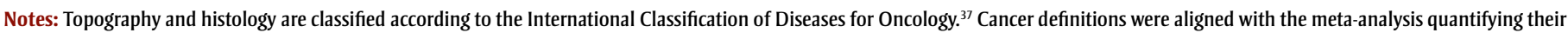
association with BMI (see Table 2). When further clarification was needed, the Surveillance, Epidemiology and End Results Program Site Recode ${ }^{38}$ was consulted.

${ }^{\text {a }}$ Defined as $\mathrm{BMI} \geq 25.00 \mathrm{~kg} / \mathrm{m}^{2}$.

${ }^{\mathrm{b}}$ Defined as per Howlader et al. ${ }^{39}$ 


\begin{tabular}{l} 
PAF $=\frac{\left[P_{\mathrm{OW}}\left(\mathrm{RR}_{\mathrm{OW}}-1\right)+\mathrm{P}_{\mathrm{OB}}\left(\mathrm{RR}_{\mathrm{OB}}-1\right)\right]}{\left[1+\left(\mathrm{P}_{\mathrm{OW}}\left(\mathrm{RR}_{\mathrm{OW}}-1\right)+\mathrm{P}_{\mathrm{OB}}\left(\mathrm{RR}_{\mathrm{OB}}-1\right)\right)\right]}$ \\
where \\
$\mathrm{P}_{\mathrm{OW}}=$ proportion classified as overweight 10 years prior to 2010 \\
$\mathrm{P}_{\mathrm{OB}}=$ proportion classified as obese 10 years prior to 2010 \\
$\mathrm{RR}_{\mathrm{OW}}=\quad \begin{array}{l}\text { relative risk for the median } \mathrm{BMI} \text { of the overweight category relative to } \\
21 \mathrm{~kg} / \mathrm{m}^{2} \text { assuming a log-linear relationship between } \mathrm{RR} \text { and } \mathrm{BMI}\end{array}$ \\
$\mathrm{RR}_{\mathrm{OB}}=\begin{array}{l}\text { relative risk for the median BMI of the obese category relative to } \\
21 \mathrm{~kg} / \mathrm{m}^{2} \text { assuming a log-linear relationship between } \mathrm{RR} \text { and } \mathrm{BMI}\end{array}$ \\
\hline
\end{tabular}

$\mathrm{RR}_{\mathrm{a}}=(\mathrm{RR})^{(\mathrm{b}-21)}$
where
$\mathrm{RR}_{\mathrm{a}}=$ relative risk for BMI category $a$
$\mathrm{RR}=$ relative risk for a one-unit increase in BMI (see Table 2)
$\mathbf{a}=$ BMI category: overweight or obese
$\mathrm{b}=$ median BMI for BMI category a

attributable cases for subgroups of interest. Because the prevalence of excess body weight varies by region and sex, and the strength of the associations between BMI and cancer can vary by sex, we estimated the proportion and number of new cancers attributable to excess body weight by province and sex; we combined and analyzed the territories as one region. To allow for a 10-year latency and more stable estimates, age groups (in years) were defined as follows: 25 to 34,35 to 44,45 to 54,55 to 64,65 to 74,75 to 84 , and $85+$. We did not estimate PAFs and attributable cases for the group aged 15 to 24 years because the prevalence of overweight and obesity in those aged 5 to 14 years in 2000 and 2001 were not available through the CCHS. To acknowledge the uncertainty in the magnitude of the relationship between excess body weight and the risk of cancer, a plausible range of values for PAFs and attributable cases were also estimated using the $95 \%$ confidence limits of the RRs in Table 2 .

\section{Results}

\section{Prevalence of excess body weight}

A detailed examination of the prevalence of excess body weight was not the primary objective of this study. Rather, we estimated prevalence of excess body weight by region, sex and age group in order to estimate PAFs. Nonetheless, a few observations warrant mention because the prevalence of excess body weight is one of the main drivers of PAFs. First, across the country in 2000 and 2001, males were more likely than females to be overweight, but the proportion classified as obese was similar across the sexes (Figure 1). Second, the proportion of adults classified as overweight varied less across the country than the proportion of adults classified as obese. Specifically, British Columbia and Quebec had the lowest prevalence of obese adults, while Saskatchewan, Manitoba, the Atlantic region and the territories had the highest prevalence.

\section{Cancers attributable to excess body weight}

PAFs, attributable cases and plausible ranges are shown by type of cancer, sex and region in Table 4. Approximately $5.7 \%$ of all cancer cases, or 9645 cancer cases, diagnosed in Canadian adults in 2010 were attributable to excess body weight. After acknowledging the uncertainty in the RR estimates, the range of plausible values for the PAF was $4.1 \%$ to $7.6 \%$ and the number of cancer cases attributable to excess body weight ranged from 6980 to 12845 . The PAF for all types of cancer combined was slightly higher in females than males $(6.5 \%$ vs. $4.9 \%)$ because of the common female-specific cancers associated with excess body weight (i.e. postmenopausal breast and uterus). When limiting the analysis to types of cancer associated with excess body weight (Table 2), the PAF for males exceeded that for females $(17.5 \%$ vs. $13.3 \%$ ) because males had higher RRs for some of the more common types of cancer (e.g. colon, rectum) and were more likely to be overweight in 2000 and 2001 .

While the proportion of all cancers attributable to excess body weight may appear modest, for some specific cancers the impact of excess weight is substantial. For instance, an estimated $42.2 \%$ of esophageal adenocarcinomas, $25.4 \%$ of kidney cancers and about $20 \%$ of gastric cardia, liver, gallbladder and colon cancers were attributable to excess body weight in males. In females, $36.1 \%$ of esophageal adenocarcinomas, $35.2 \%$ of uterine cancers and almost 1 in 4 kidney and gallbladder cancers were attributable to excess body weight. Irrespective of type of cancer or sex, PAFs were lowest in British Columbia and Quebec and highest in the Prairies (except Alberta) and the Atlantic region, generally reflecting the prevalence of excess body weight in those regions in 2000 and 2001.

Finally, the distinction between PAFs and attributable cases needs to be acknowledged. Cancers with substantial case counts attributable to excess body weight do not necessarily have the highest PAFs. For males, colon cancer ranked fourth in terms of PAF but first in terms of number of attributable cases, accounting for about a third of all cancer cases attributable to excess body weight. For females, postmenopausal breast cancer ranked seventh in terms of PAF but second in terms of attributable cases, accounting for about a third of all cancer cases attributable to excess body weight.

\section{Discussion}

An estimated $5.7 \%$ or 1 in 18 cancer cases diagnosed in Canadian adults in 2010 were attributable to excess body weight $\left(B M I \geq 25.00 \mathrm{~kg} / \mathrm{m}^{2}\right)$. This translates to nearly 10000 cancer cases, a number expected to rise as the prevalence of overweight and obesity rises in Canada. After acknowledging the uncertainty in the magnitude of the relationship between excess body weight and the risk of cancer, the PAF ranged from $4.1 \%$ to $7.6 \%$ and attributable cancer cases ranged from 6980 to 12845 .

PAFs varied by type of cancer, sex and region. In males, PAFs were highest for 


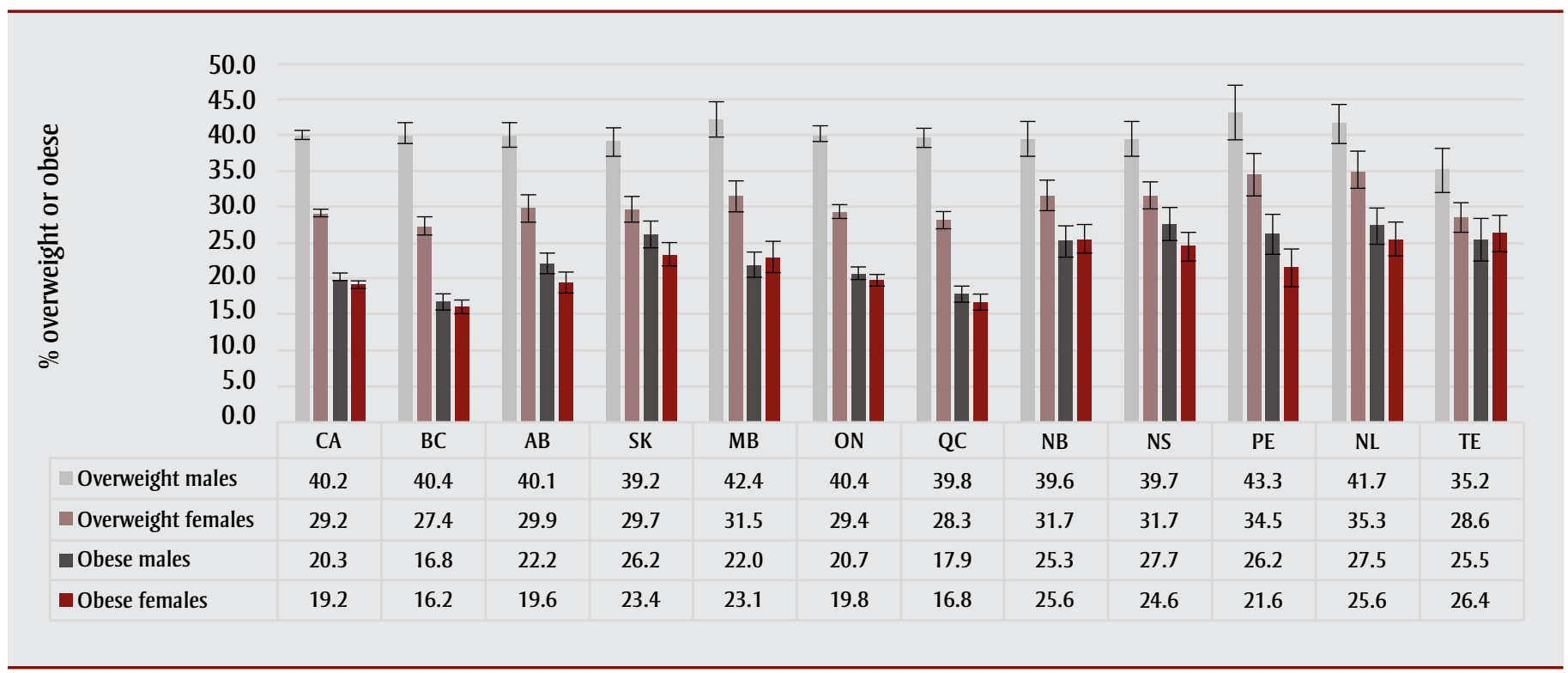

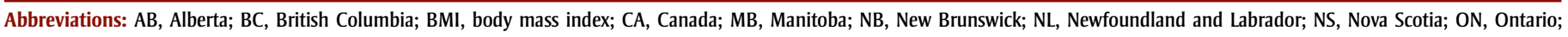
PE, Prince Edward Island; QC, Quebec; SK, Saskatchewan; TE, all three Canadian territories combined.

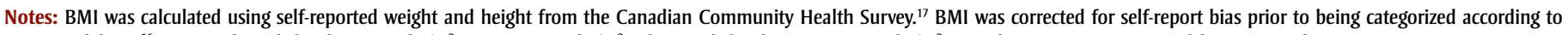
WHO guidelines. ${ }^{16}$ Overweight is defined as $25.00 \mathrm{~kg} / \mathrm{m}^{2} \leq \mathrm{BMI} \leq 29.99 \mathrm{~kg} / \mathrm{m}^{2}$. Obese is defined as $\mathrm{BMI} \geq 30.00 \mathrm{~kg} / \mathrm{m}^{2}$. Error bars represent $95 \%$ confidence intervals.

esophageal adenocarcinoma (42.2\%), kidney cancer $(25.4 \%)$, and cancers of the gastric cardia, liver, colon and gallbladder (about 1 in 5). In females, PAFs were highest for esophageal adenocarcinoma $(36.1 \%)$, uterine cancer $(35.2 \%)$, and cancers of the gallbladder and kidney (about 1 in 4). In general, PAFs were highest in the Prairies (except Alberta) and Atlantic Canada, and lower in British Columbia and Quebec, reflecting the regional prevalence of excess body weight in 2000 and 2001.

Comparisons with previous research are complicated because PAFs are affected by a variety of factors such as the number of different cancers included, the RR assigned to the overweight and obese categories, and the prevalence of overweight and obesity in the population. Arnold et al. ${ }^{12}$ estimated the proportion of cancers attributable to excess body weight in 2012 using model-based BMI distributions, a theoretical-minimum-risk BMI distribution $\left(\right.$ mean $=22 \mathrm{~kg} / \mathrm{m}^{2}, \mathrm{SD}=1 \mathrm{~kg} / \mathrm{m}^{2}$ ), and cancer-specific projected counts. For males, our PAFs were very similar to the estimates of Arnold et al. ${ }^{12}$ for Canada. For females, however, the PAFs in the study by Arnold et al. ${ }^{12}$ were notably higher than ours for esophageal adenocarcinoma (44.0\% vs. $36.1 \%)$, gallbladder $(49.0 \%$ vs. $23.7 \%)$, kidney ( $31.0 \%$ vs. $23.0 \%)$ and uterus ( $43.0 \%$ vs. $35.2 \%)$. Some of these differences can be attributed to methodological differences, including the aforementioned use of modelled data with its underlying assumptions, and the RR estimates used. For gallbladder and kidney, Arnold et al. ${ }^{12}$ used RR estimates from Renehan et al., ${ }^{8}$ which were higher than more recent estimates reported by CUP. The difference was substantial for gallbladder: 1.59 versus 1.25 per $5 \mathrm{~kg} / \mathrm{m}^{2}$.

Some of our cancer- and sex-specific PAFs also differed from Brenner's ${ }^{13}$ estimates for Canada in 2007. Our PAF for male esophageal adenocarcinoma was higher (42.2\% vs. $32.3 \%)$ after we made additional calculations, based on assumptions, to adjust Brenner's estimate for all esophageal cancers. Our PAF for gallbladder cancer was higher for both males $(20.2 \%$ vs. $13.9 \%)$ and females $(23.7 \%$ vs. $13.0 \%)$. Our colon cancer estimate was substantially higher than Brenner's for males $(20.5 \%$ vs. $10.6 \%)$ but not females $(9.7 \%$ vs. $8.9 \%)$.

Several factors, in addition to the more recent time period examined in this study, may have contributed to these differences. First, for colon cancer, we used more recent sex-specific RR estimates, which are higher for males than females. Second, our method of assigning RRs to the overweight and obese category acknowledged the distribution of BMIs within the category, whereas Brenner ${ }^{13}$ used RR estimates for a $5 \mathrm{~kg} / \mathrm{m}^{2}$ increase for the overweight category and squared this for the obese category. Third, Brenner's estimates were based on unadjusted BMIs, whereas our study adjusted for the bias in selfreported height and weight. Finally, Brenner's most specific PAFs, upon which all other PAFs and attributable cases were calculated, did not acknowledge region, whereas ours did.

Finally, previously published PAFs for Ontario in 2010 by Cancer Care Ontario ${ }^{14}$ were similar to ours for pancreas $(11.3 \%$ vs. $10.4 \%$, respectively), kidney $(22.8 \%$ vs. $24.7 \%)$, postmenopausal breast $(10.3 \%$ after excluding breast cancers diagnosed prior to age 50 vs. 9.9\%) and uterus (33.0\% vs. $35.6 \%)$, but differed for esophageal adenocarcinoma $(34.1 \%$ after excluding non-adenocarcinoma cases vs. $41.7 \%$ ) and colorectal $(8.2 \%$ vs. $15.3 \%$ for colon and $8.5 \%$ for rectum). Cancer Care Ontario corrected BMIs for self-report bias but other differences in methodology existed: we used sex-specific RR estimates including separate estimates for colon and rectal cancers, whereas Cancer Care Ontario did not; we used the median BMI of a weight category to assign its RR, whereas Cancer Care Ontario used an approach similar to 


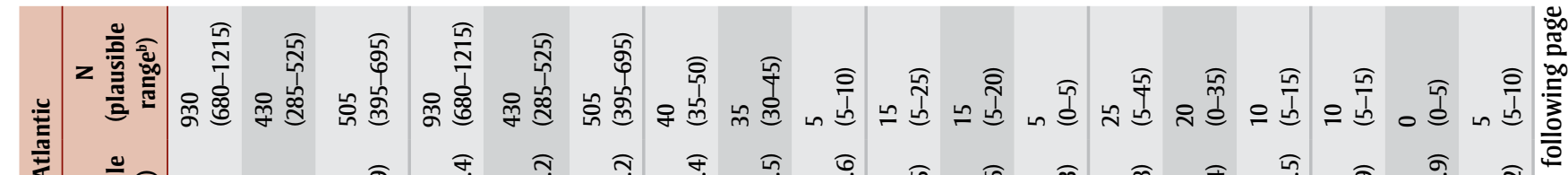

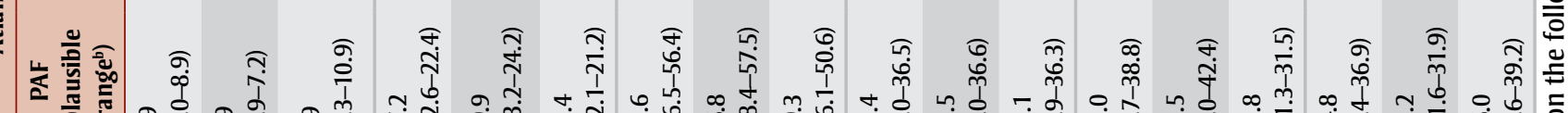

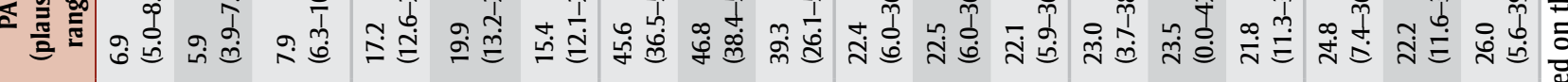

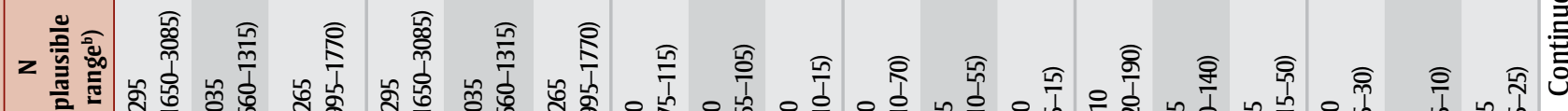

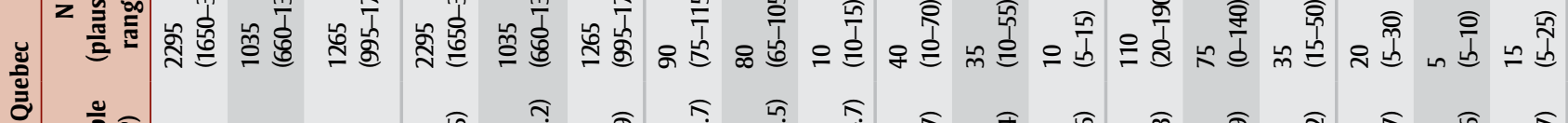

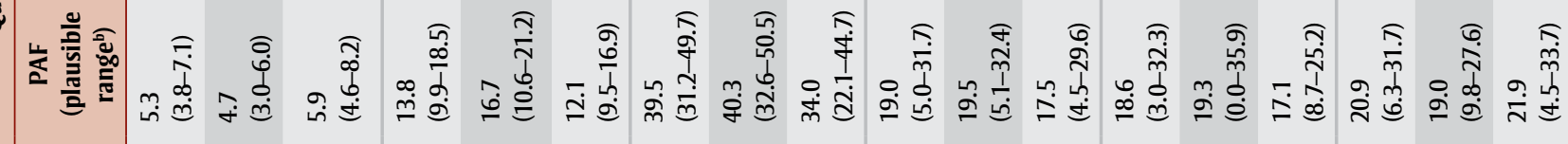

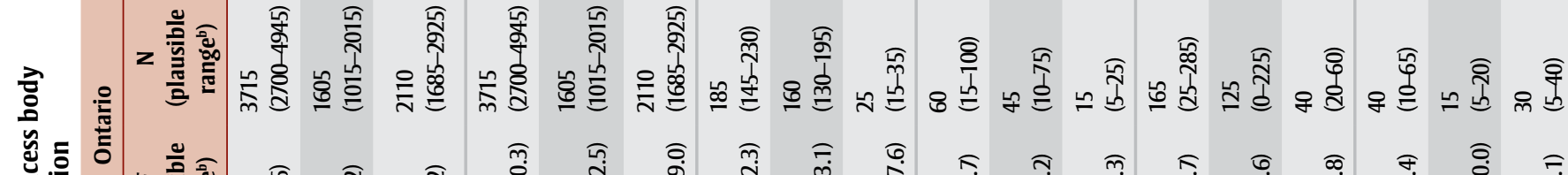

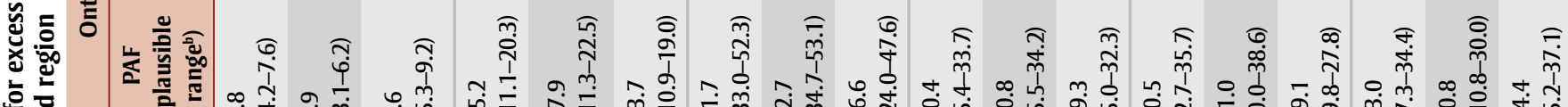

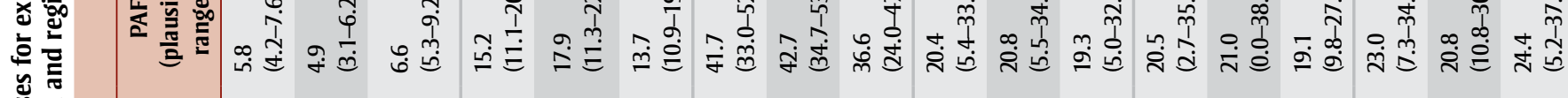

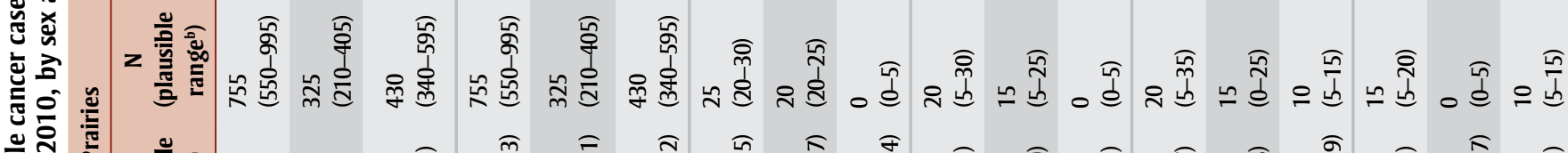

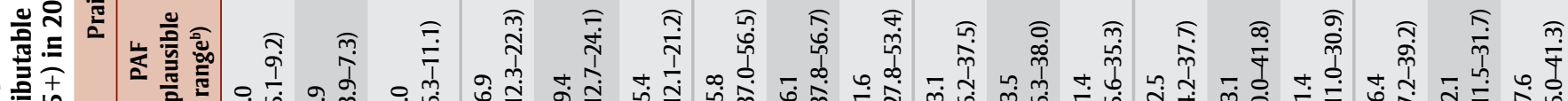

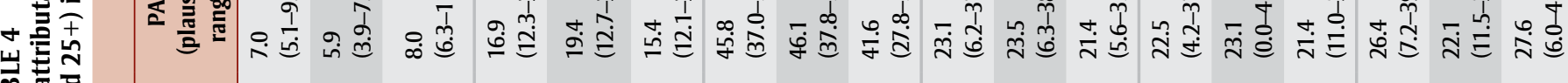

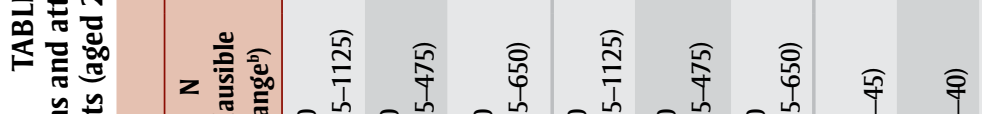

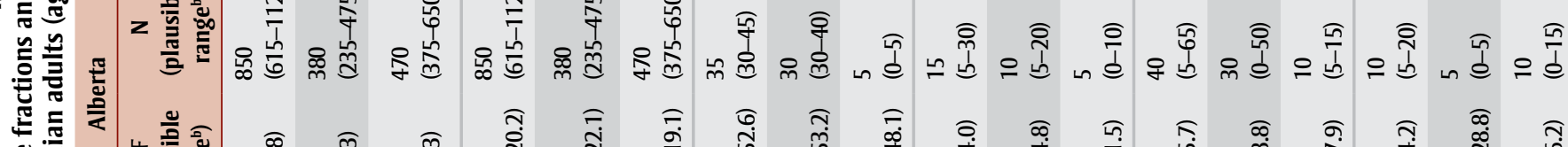

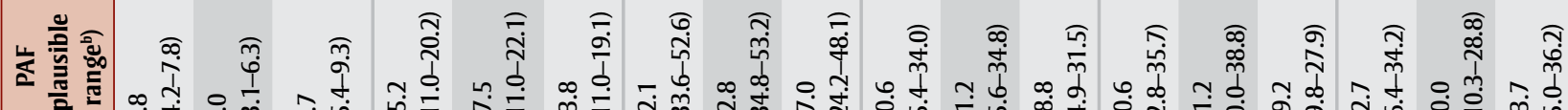

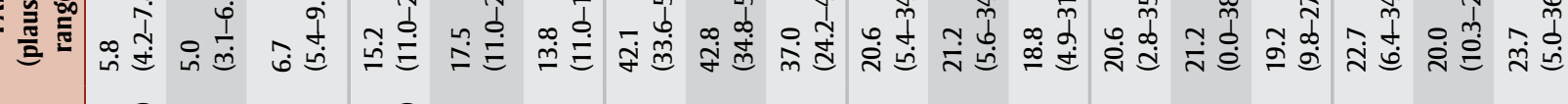

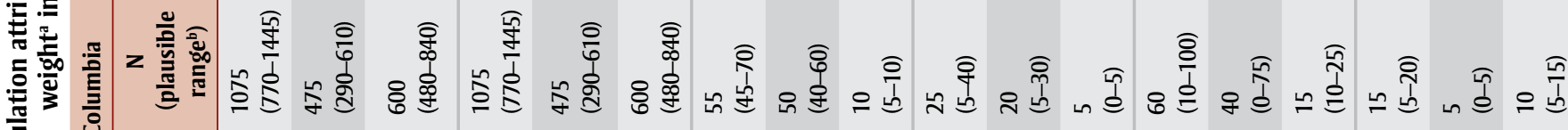
言

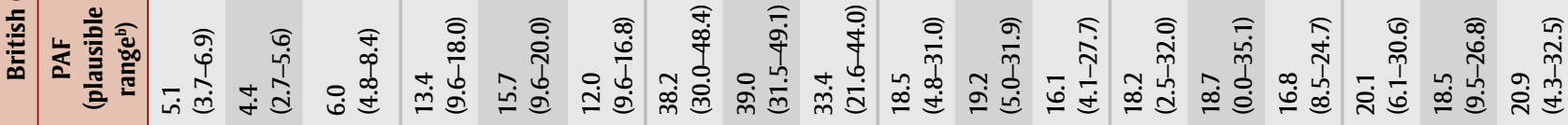

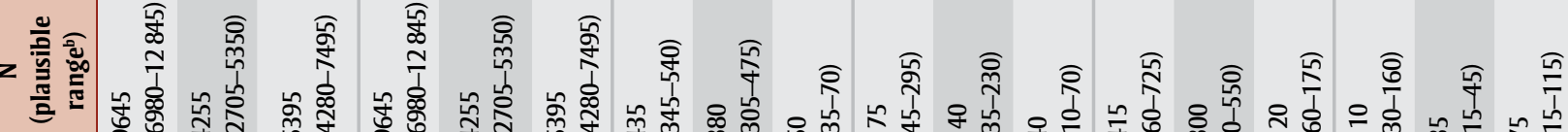

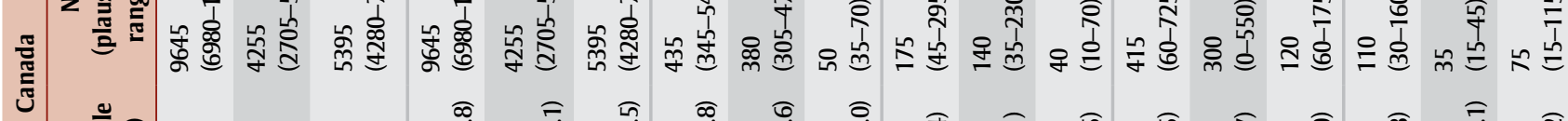

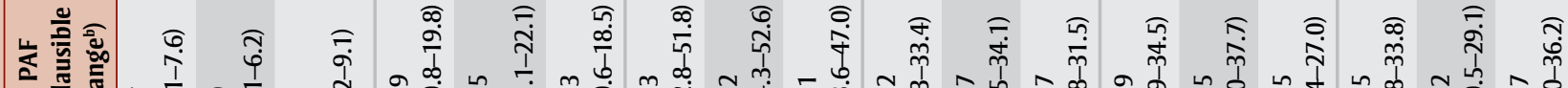

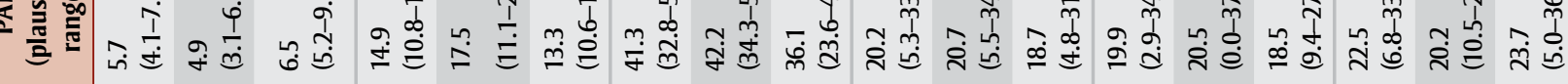

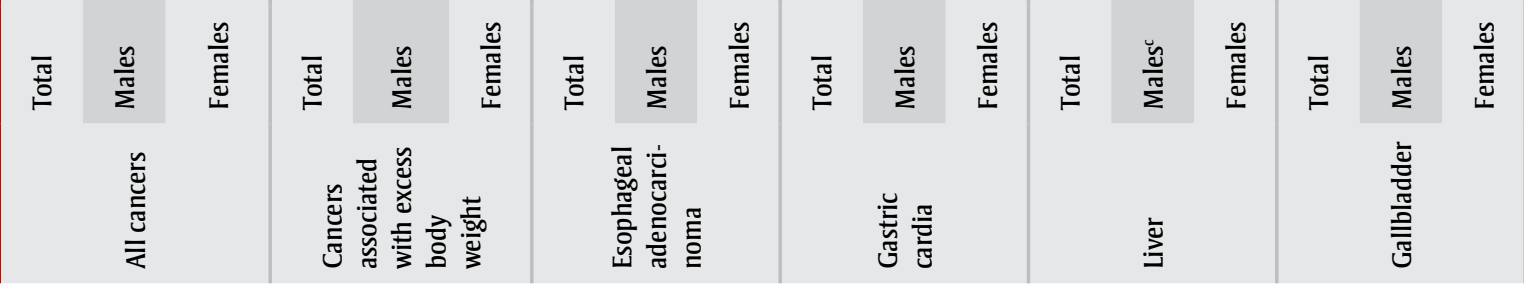




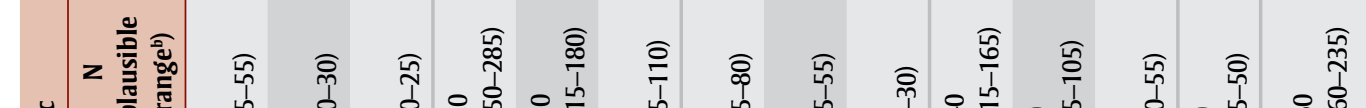
羍

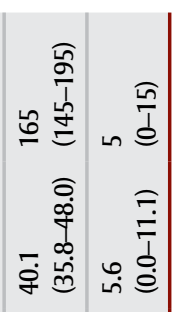

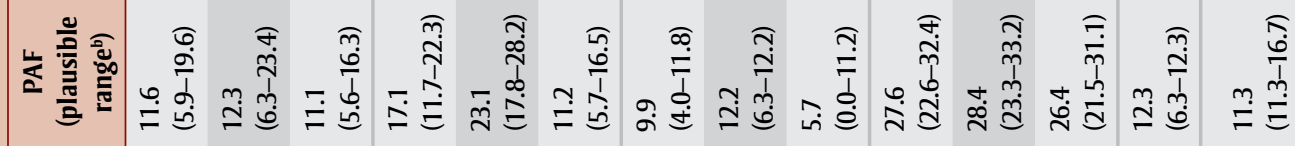

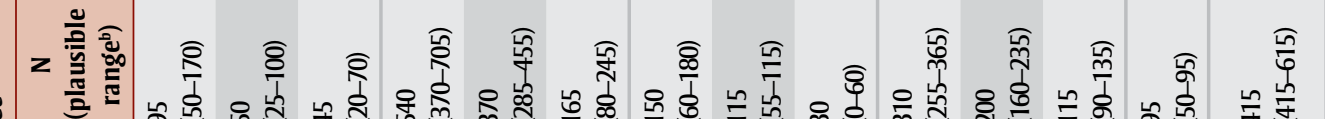
赔

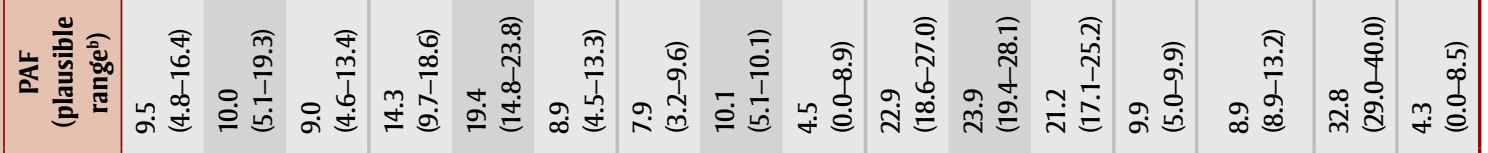

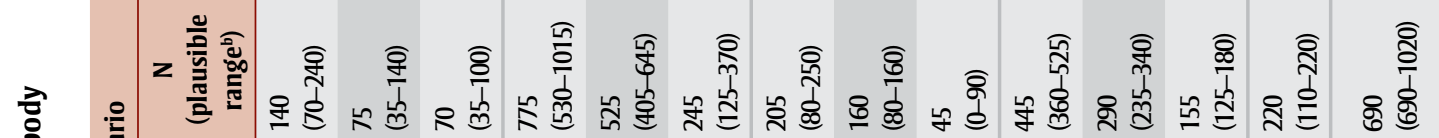

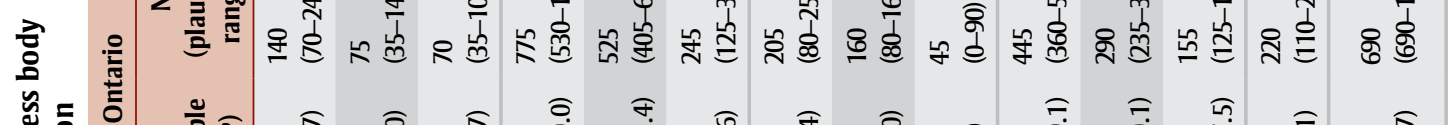

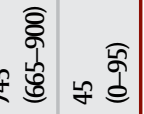

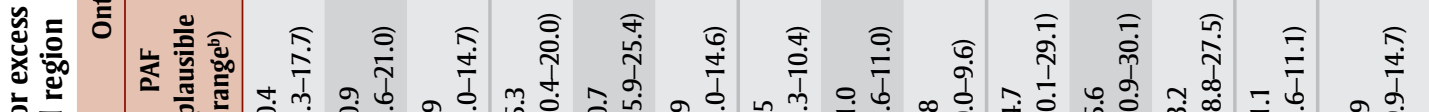

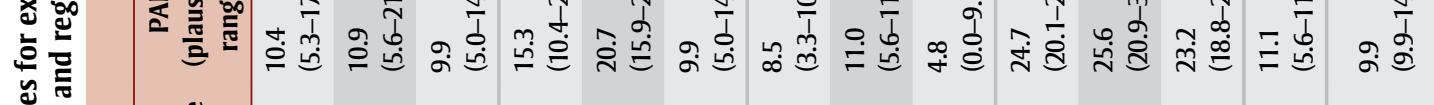

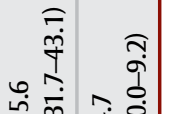

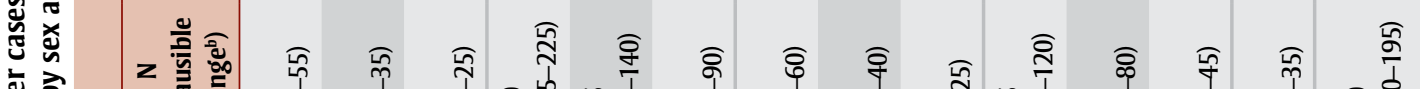

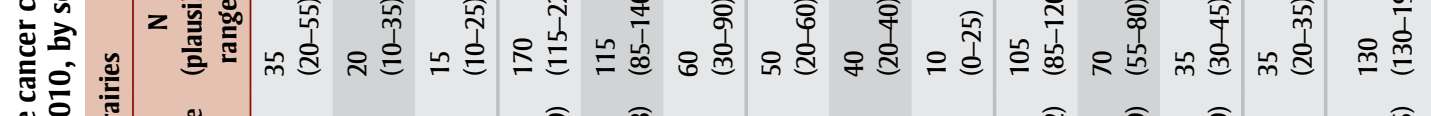

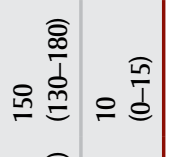

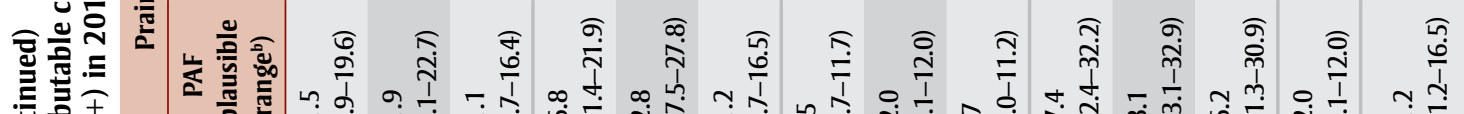

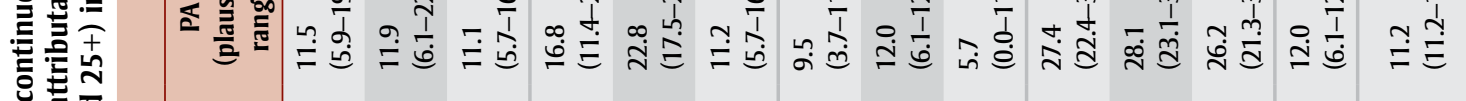

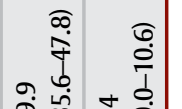

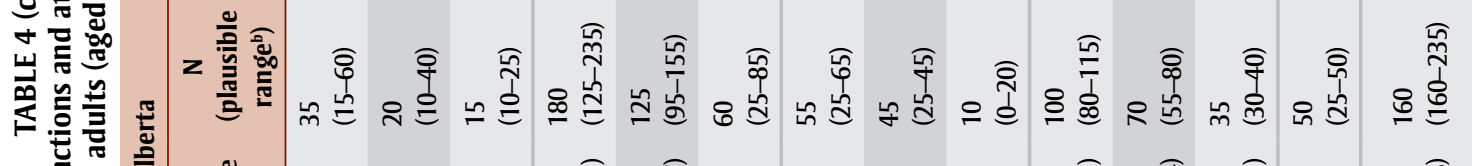

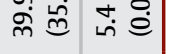

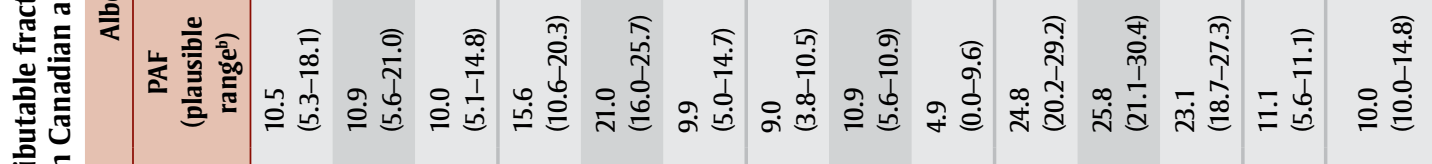
的部

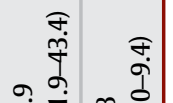

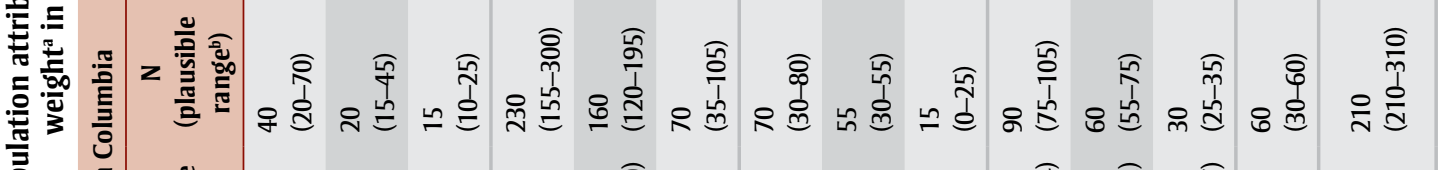

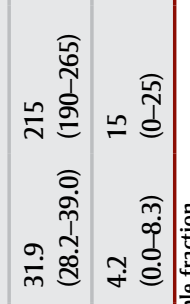

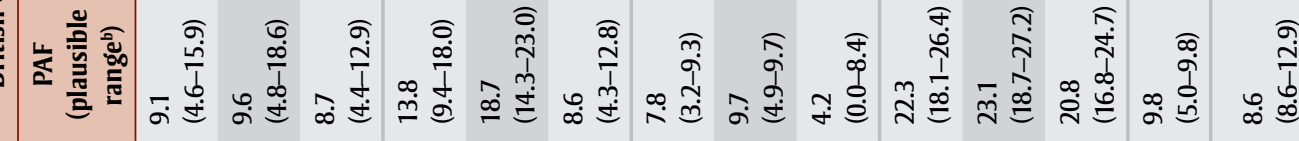

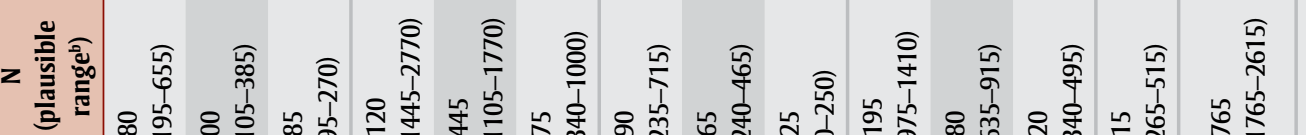

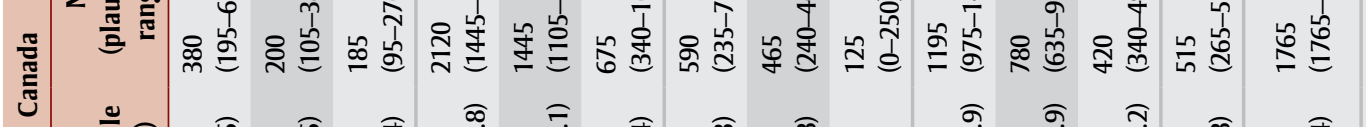

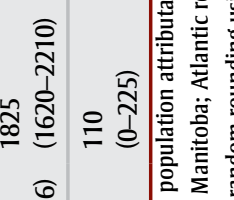

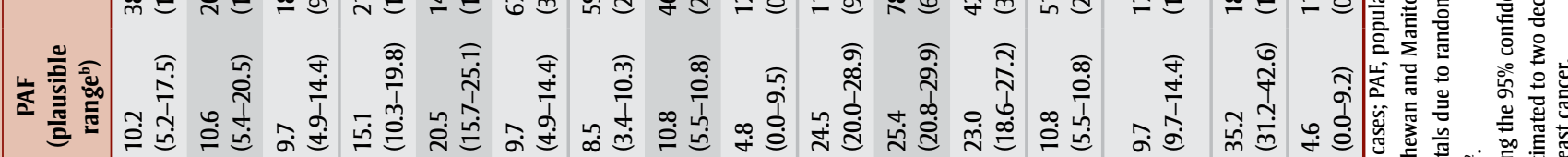

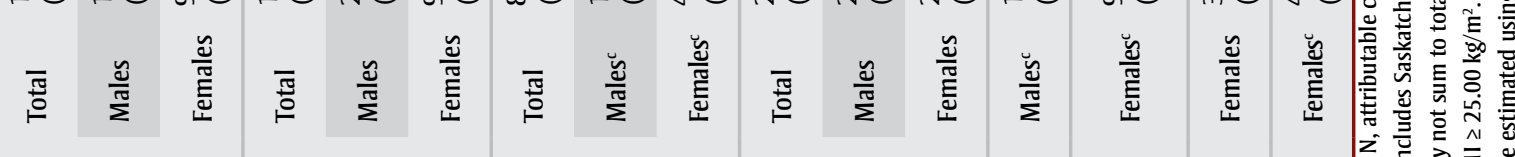

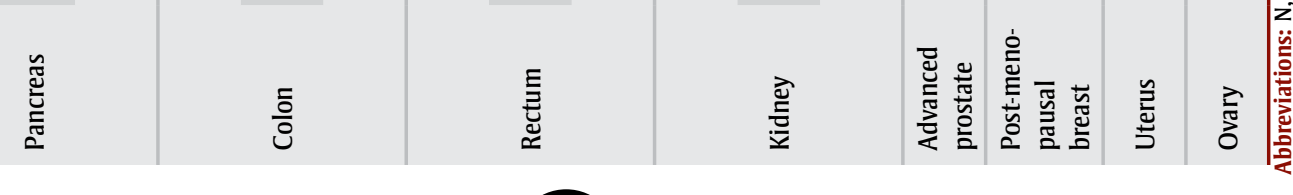


Brenner's; ${ }^{13}$ and we obtained Ontario cancer counts from a snapshot of the CCR released in September 2012, whereas Cancer Care Ontario obtained cancer counts directly from the Ontario Cancer Registry.

\section{Strengths and limitations}

This study has several strengths compared to previously published Canadian research. First, our study included PAFs for additional cancers with strong evidence of a causal relationship with excess body weight. Second, the RR assigned to the overweight and obese categories acknowledged the BMI distribution within the categories relative to an optimal BMI $\left(21 \mathrm{~kg} / \mathrm{m}^{2}\right)$. Third, we provided PAFs and counts of cancer cases attributable to excess body weight for regions within Canada in addition to the whole country. Fourth, we corrected BMI for self-report bias using formulas developed and validated with CCHS respondents. Using corrected BMIs increased the overall PAF by about $20 \%$ from $4.8 \%$ (males $4.2 \%$, females $5.4 \%$ ) to $5.7 \%$ (males $4.9 \%$, females $6.5 \%$ ).

Some limitations, however, should be acknowledged when interpreting the results of this study.

First, BMI does not distinguish between weight associated with muscle or fat; thus, the relationship between BMI and body fat varies with body build, sex, age and ethnicity. ${ }^{16}$

Second, BMI measurements at a specific point in time do not acknowledge potential cancer-specific, time-dependent effects of high BMI on cancer risk. Some research indicates that the risk of cancer from high BMI increases with the number of years lived with a high BMI, and that young adult BMI may be more strongly associated with cancer risk than BMI later in life. ${ }^{41-43}$

Third, the association between BMI and cancer may differ across populations. ${ }^{44}$ The measures of association used in this study were not specific to Canada. Nevertheless, Renehan et al. $^{8}$ found that, for many cancers, the increased risk associated with increasing BMI were consistent across populations. A notable exception was breast cancer: increasing BMI increased the risk of pre-menopausal breast cancer in Asia-Pacific regions but decreased the risk in other regions; and the postmenopausal breast cancer risk associated with increasing BMI was greater in Asia-Pacific regions than other regions. The RR estimate used for postmenopausal breast cancer in this study, however, was consistent with that for North America.

Fourth, RRs used in Equation 3 should not be adjusted for confounding. ${ }^{4}$ However, appropriate use of Equation 3 with adjusted RRs would require availability of exposure and disease data stratified by confounding variable(s), a situation generally not available. Interestingly, Renehan et al. ${ }^{8}$ reported that repetition of analyses with minimally adjusted RRs rather than maximally adjusted RRs did not produce different results with respect to the association between BMI and cancer. Further, calculating PAFs within age- and sex-specific strata, two variables commonly used to adjust RRs, may mitigate the impact of using adjusted RRs in this study. ${ }^{44}$

Fifth, additional types of cancer (meningioma, thyroid and multiple myeloma), not included in this study, have recently been identified as having sufficient evidence of an association with excess body weight. Consequently, the PAFs and attributable cases reported in this study are probably underestimates of the true cancer burden of excess body weight in the Canadian adult population. ${ }^{10}$

Sixth, although the CCHS participation rate was high $(84.7 \%)$, samples are vulnerable to nonresponse bias. PAFs and attributable cases reported in this study will be biased downward if nonparticipants were more likely to be overweight or obese than participants and vice versa.

Seventh, it should be noted that PAFs are not exact, error-free estimates. Rather, uncertainty exists due to variation in the RRs used and in the prevalence of overweight and obesity estimates, and the statistical uncertainty inherent in estimation. To acknowledge this uncertainty, plausible ranges were estimated for PAFs and attributable cancer cases using the $95 \%$ confidence limits of the RRs in Table 2.

\section{Conclusion}

An estimated $5.7 \%$ (1 in 18) of all new cancer cases diagnosed in Canadian adults in 2010 were attributable to high BMI after correcting for bias in self-reported height and weight. Since the prevalence of overweight and obesity continues to rise in Canada, the proportion of new cancer cases attributable to excess body weight will continue to rise in the near future. Increased public awareness regarding the relationship between body weight and cancer and effective interventions for maintaining healthy body weight are needed. Considering the interrelation of body weight, activity level and diet, public health initiatives promoting healthy body weight will likely result in additional benefits through increased activity levels and healthier diets.

\section{Conflicts of interest}

The authors declare no conflicts of interest.

\section{Authors' contributions}

Both authors contributed to study design, interpretation of the results, drafting the manuscript and critical revisions. DZ performed the analyses.

\section{References}

1. Canadian Cancer Society's Advisory Committee on Cancer Statistics. Canadian cancer statistics 2015. Toronto (ON): Canadian Cancer Society; 2015. $151 \mathrm{p}$.

2. Statistics Canada. CANSIM database: Table 102-0552: Deaths and mortality rate, by selected grouped causes and sex, Canada, provinces and territories [Internet]. Ottawa (ON): Statistics Canada; [modified 2017 Mar 8; cited 2016 May 2]. Available from: http:// www 5.statcan.gc.ca/cansim/a26 ?lang = eng\&retrLang = eng\&id $=1020552 \& \&$ pattern $=\&$ stByVal $=1 \& \mathrm{p} 1=1 \& \mathrm{p} 2=-1 \&$ tabMode $=$ dataTable $\& \operatorname{csid}=$

3. Last JM, editor. A dictionary of epidemiology. 3rd ed. New York (NY): Oxford University Press; 1995. 208 p.

4. Rockhill B, Newman B, Weinberg C. Use and misuse of population attributable fractions. Am J Public Health. 1998;88(1):15-9.

5. Parkin DM, Boyd L, Walker LC. 16. The fraction of cancer attributable to lifestyle and environmental factors in the UK in 2010: summary and conclusions. Br J Cancer. 2011;105 Suppl 2: S77-S81. 
6. International Agency for Research on Cancer (IARC), World Health Organization. IARC handbooks of cancer prevention. Volume 6: Weight control and physical activity. Lyon (FR): IARC Press; 2002. 326 p.

7. World Cancer Research Fund, American Institute for Cancer Research (AICR). Food, nutrition, physical activity, and the prevention of cancer: a global perspective. Washington (DC): AICR; 2007. Chapter 2, The cancer process; p. 30-46.

8. Renehan AG, Tyson $M$, Egger $M$, Heller RF, Zwahlen M. Body-mass index and incidence of cancer: a systematic review and meta-analysis of prospective observational studies. Lancet. 2008;371(9612):569-78.

9. Schmid D, Ricci C, Behrens G, Leitzmann MF. Adiposity and risk of thyroid cancer: a systematic review and meta-analysis. Obes Rev. 2015; 16(12):1042-54.

10. Lauby-Secretan B, Scoccianti C, Loomis $\mathrm{D}$, et al. Body fatness and cancerviewpoint of the IARC Working Group. N Engl J Med. 2016;375(8):794-8.

11. World Health Organization, International Agency for Research on Cancer. IARC monographs on the evaluation of carcinogenic risks to humans: internal report 14/002. Lyon (FR): IARC Press; 2014. 60 p.

12. Arnold M, Pandeya N, Byrnes G, et al. Global burden of cancer attributable to high body-mass index in 2012: a population-based study. Lancet Oncol. 2015;16(1):36-46.

13. Brenner DR. Cancer incidence due to excess body weight and leisure-time physical inactivity in Canada: implications for prevention. Prev Med. 2014;66:131-9.

14. Cancer Care Ontario. Cancer risk factors in Ontario: healthy weights, healthy eating, and active living. Toronto (ON): Queen's Printer for Ontario; 2015. 62 p.

15. Statistics Canada. Overweight and obese adults (self-reported), 2014 [Internet]. Ottawa (ON): Statistics Canada; modified 2015 Nov 27 [cited 2015 Nov 22]. Available from: http:// www.statcan.gc.ca/pub/82-625-x /2015001/article/14185-eng.htm
16. WHO Consultation on Obesity. Obesity: preventing and managing the global epidemic. Geneva $(\mathrm{CH})$ : World Health Organization; 2000. 252 p.

17. Statistics Canada. Canadian Community Health Survey-Annual Component (CCHS) [Internet]. Ottawa (ON): Statistics Canada; 2001 [modified 2007 Oct 24; cited 2015 Nov 26]. Available from: http://www23.statcan.gc.ca /imdb/p2SV.pl?Function = getSurvey $\& I d=3359$

18. Shields M, Gorber SC, Tremblay MS. Estimates of obesity based on selfreport versus direct measures. Health Rep. 2008;19(2):61-76.

19. Gorber SC, Shields M, Tremblay MS, McDowell I. The feasibility of establishing correction factors to adjust self-reported estimates of obesity. Health Rep. 2008;19(3):71-82.

20. Shields M, Gorber SC, Janssen I, Tremblay MS. Bias in self-reported estimates of obesity in Canadian health surveys: an update on correction equations for adults. Health Rep. 2011;22(3):35-45.

21. Kendall BJ, Wilson LF, Olsen CM, et al. Cancers in Australia in 2010 attributable to overweight and obesity. Aust N Z J Public Health. 2015;39(5): 452-7.

22. Parkin DM, Boyd L. 8. Cancers attributable to overweight and obesity in the UK in 2010. Br J Cancer. 2011;105 Suppl 2:S34-S37.

23. World Cancer Research Fund (WCRF) International. Continuous Update Project findings and reports [Internet]. London (UK): WCRF International; 2017 [cited 2016 Dec 1]. Available from: http://www.wcrf.org/int/research -we-fund/continuous-update-project -findings-reports

24. World Cancer Research Fund (WCRF) International, American Institute for Cancer Research. Continuous Update Project report: Diet, nutrition, physical activity and oesophageal cancer [Internet]. London (UK): WCRF International; 2016 [cited 2016 Dec 1]. Available from: http://www.wcrf .org/sites/default/files/CUP \% 20 OESOPHAGEAL_WEB.pdf
25. World Cancer Research Fund (WCRF) International, American Institute for Cancer Research. Continuous Update Project report: Diet, nutrition, physical activity and stomach cancer [Internet]. London (UK): WCRF International; 2016 [cited 2016 Dec 1]. Available from: http://wcrf.org /sites/default/files/Stomach-Cancer -2016-Report.pdf

26. World Cancer Research Fund (WCRF) International, American Institute for Cancer Research. Continuous Update Project report: Diet, nutrition, physical activity and liver cancer [Internet]. London (UK): WCRF International; 2015 [cited 2016 Dec 1]. Available from: http://wcrf.org/sites/default /files/Liver-Cancer-2015-Report.pdf

27. World Cancer Research Fund (WCRF) International, American Institute for Cancer Research. Continuous Update Project report: Diet, nutrition, physical activity and gallbladder cancer [Internet]. London (UK): WCRF International; 2015 [cited 2016 Dec 1]. Available from: http://www.wcrf .org/sites/default/files/Gallbladder -Cancer-2015-Report.pdf

28. World Cancer Research Fund (WCRF), American Institute for Cancer Research. Continuous Update Project report. Food, nutrition, physical activity, and the prevention of pancreatic cancer [Internet]. London (UK): WCRF; 2012 [cited 2016 Dec 1]. Available from: http://wcrf.org/sites/default/files /Pancreatic-Cancer-2012-Report.pdf

29. World Cancer Research Fund (WCRF), American Institute for Cancer Research. Continuous Update Project report: Food, nutrition, physical activity, and the prevention of colorectal cancer [Internet]. London (UK): WCRF; 2011 [cited 2016 Dec 1]. Available from: http://wcrf.org/sites/default/files /Colorectal-Cancer-2011-Report.pdf

30. World Cancer Research Fund (WCRF) International, American Institute for Cancer Research. Continuous Update Project report: Diet, nutrition, physical activity and kidney cancer [Internet]. London (UK): WCRF International; 2015 [cited 2016 Dec 1]. Available from: http://wcrf.org /sites/default/files/Kidney-Cancer -2015-Report.pdf 
31. World Cancer Research Fund (WCRF) International, American Institute for Cancer Research. Continuous Update Project report: Diet, nutrition, physical activity, and prostate cancer [Internet]. London (UK): WCRF International; 2014 [cited 2016 Dec 1]. Available from: www.wcrf.org/sites /default/files/Prostate-Cancer-2014 -Report.pdf

32. World Cancer Research Fund (WCRF), American Institute for Cancer Research. Continuous Update Project report. Food, nutrition, physical activity, and the prevention of breast cancer [Internet]. London (UK): WCRF; 2010 [cited 2016 Dec 1]. Available from: http://www.wcrf.org/sites/default /files/Breast-Cancer-2010-Report.pdf

33. World Cancer Research Fund (WCRF), American Institute for Cancer Research. Continuous Update Project report. Food, nutrition, physical activity, and the prevention of endometrial cancer [Internet]. London (UK): WCRF; 2013 [cited 2016 Dec 1]. Available from: http://www.wcrf.org/sites/default /files/Endometrial-Cancer-2013 -Report.pdf

34. World Cancer Research Fund (WCRF), American Institute for Cancer Research. Continuous Update Project report. Food, nutrition, physical activity, and the prevention of ovarian cancer [Internet]. London (UK): WCRF; 2014 [cited 2016 Dec 1]. Available from: http://www.wcrf.org/sites/default /files/Ovarian-Cancer-2014-Report .pdf

35. International Agency for Research on Cancer, World Health Organization, International Association of Cancer Registries, European Network of Cancer Registries. International rules for multiple primary cancers (ICD-O). 3rd ed. Lyon (FR): International Agency for Research on Cancer; 2004 [Internal Report No. 2004/02].

36. Statistics Canada. CANSIM database: Table 103-0550: New cases of primary cancer (based on the August 2015 CCR tabulation file), by cancer type, age group and sex, Canada, provinces and territories [Internet]. Ottawa (ON): Statistics Canada; [modified 2017 Feb 21; cited 2016 May 2]. Available from: http://www5.statcan.gc.ca/cansim /a26?lang $=$ eng\&retrLang $=$ eng\&id $=1030550 \& \&$ pattern $=\&$ stByVal $=1 \& \mathrm{p} 1$ $=1 \& \mathrm{p} 2=-1 \&$ tabMode $=$ dataTable $\&$ csid $=$
37. World Health Organization. International classification of diseases for oncology (ICD-O). 3rd ed., 1st revision. Geneva $(\mathrm{CH})$ : World Health Organization; 2013. 252 p.

38. National Cancer Institute Surveillance, Epidemiology and End Results Program. Site recode ICD-O-3/WHO 2008 definition [Internet]. Bethesda (MD): National Cancer Institute; [cited 2016 May 2]. Available from: http://seer .cancer.gov/siterecode/icdo3 dwhoheme/index.html

39. Howlader N, Noone AM, Krapcho M, et al., editors. SEER cancer statistics review, 1975-2013 [Internet]. Bethesda (MD): National Cancer Institute, 2016 [based on November 2015 SEER data submission; cited 2016 Dec 2]. Available from: http://seer.cancer.gov/csr /1975_2013

40. Philip W, James T, Jackson-Leach R, et al. Overweight and obesity (high body mass index). In: Ezzati $\mathrm{M}$, Lopez AD, Rodgers A, Murray CJL, editors. Comparative quantification of health risks. Geneva $(\mathrm{CH})$ : World Health Organization; 2004:497-596.

41. Abdullah A, Wolfe R, Stoelwinder JU et al. The number of years lived with obesity and the risk of all-cause and cause-specific mortality. Int J Epidemiol. 2011;40(4):985-96.

42. Stolzenberg-Solomon RZ, Schairer C, Moore S, Hollenbeck A, Silverman DT. Lifetime adiposity and risk of pancreatic cancer in the NIH-AARP Diet and Health Study cohort. Am J Clin Nutr. 2013;98(4):1057-65.

43. Leitzmann MF, Koebnick C, Danforth $\mathrm{KN}$, et al. Body mass index and risk of ovarian cancer. Cancer. 2009; $115(4): 812-22$.

44. Flegal KM, Panagiotou OA, Graubard BI. Estimating population attributable fractions to quantify the health burden of obesity. Ann Epidemiol. 2015; 25(3):201-7. 